\title{
Left ventricular reverse remodeling in patients with anterior wall ST-segment elevation acute myocardial infarction treated with primary percutaneous coronary intervention
}

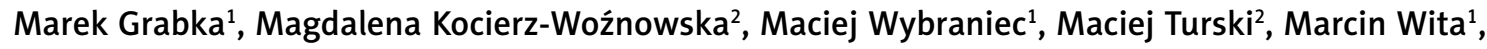 \\ Krystian Wita ${ }^{1}$, Katarzyna Mizia-Stec ${ }^{1}$ \\ ${ }^{1} 1^{\text {st }}$ Department of Cardiology, Upper Silesian Medical Centre, Katowice, Poland \\ ${ }^{2}$ Department of Cardiac Rehabilitation, Upper Silesian Medical Centre, Katowice, Poland
}

Adv Interv Cardiol 2018; 14, 4 (54): 373-382

DOI: https://doi.org/10.5114/aic.2018.79867

\begin{abstract}
A bstract
Introduction: The study aimed to evaluate the prevalence and predictors of left ventricular (LV) reverse remodeling and its impact on long-term prognosis in patients with anterior ST-segment elevation myocardial infarction (STEMI).

Aim: To assess the percentage of reverse remodeling and its prognostic factors in anterior STEMI patients.

Material and methods: This observational study included 40 patients with first ever STEMI of the anterior wall. LV reverse remodeling was defined as the reduction of left ventricular end-systolic volume ( $\triangle$ LVESV) by $\geq 10 \%$ in $3 \mathrm{D}$ transthoracic echocardiography (3D-TTE) at 3-month follow-up. 3D-TTE and speckle tracking imaging were performed during index hospitalization, while 3D-TTE and cardiac magnetic resonance (CMR) were performed at 3 months following the procedure. Patients were followed up for a median time of 3.4 years in order to evaluate major adverse cardiovascular events.

Results: Left ventricular reverse remodeling at 3-month follow-up was confirmed in 15 (37.5\%) patients. The presence of reverse remodeling was predicted by lower troponin levels (unit $\mathrm{OR}=0.86, p=0.02$ ), lower sum of ST-segment elevations before (unit $\mathrm{OR}=0.87, p=0.03$ ) and after $\mathrm{PCl}$ (unit $\mathrm{OR}=0.40, p=0.03$ ), lower maximal ST-segment elevation after $\mathrm{PCI}$ (unit $\mathrm{OR}=0.01, p=0.03$ ), lower wall motion score index (unit $\mathrm{OR} 0.40, p=0.03$ ) and more negative anterior wall global longitudinal strain (unit $\mathrm{OR}=0.88$, $p=0.045)$. Nine MACE were reported in the without reverse remodeling group only. Non-significantly better event-free survival in the reverse remodeling group was demonstrated (log-rank $p=0.07$ ).

Conclusions: Development of reverse modeling in patients with optimal revascularization and tailored pharmacotherapy is relatively high. Further studies are warranted in order to adjudicate its prognostic role for the prediction of adverse events.
\end{abstract}

Key words: global longitudinal strain, cardiac magnetic resonance imaging, acute myocardial infarction/ST-segment elevation myocardial infarction, reverse remodeling, 3D transthoracic echocardiography, anterior global longitudinal strain.

S u m m a ry

The publication concerns the novel issue connected with late follow-up after myocardial infarction - reverse remodeling. It leads to improvement of myocardial function and takes place in the first 3-6 months after myocardial infarction (MI). There are limited data about reverse remodeling after $\mathrm{MI}$ and its influence in terms of clinical effects, adverse events and quality of life. The paper presents prediction of reverse remodeling in a small, narrowly selected group of ST-segment elevation myocardial infarction patients.

\section{Introduction}

Despite rapid progress in percutaneous coronary interventions $(\mathrm{PCl})$, a certain proportion of patients with acute coronary syndromes (ACS) exhibit clinically relevant left ventricular (LV) dysfunction within the area supplied by the affected coronary artery. According to former

Corresponding author:

Marek Grabka MD, PhD, $1^{\text {st }}$ Department of Cardiology, Upper Silesian Medical Centre, 45-47 Ziołowa St, 40-635 Katowice, Poland, phone: +48 500228 614, e-mail: marekgrabka@interia.pl

Received: 27.05.2018, accepted: 17.09.2018. 
studies, about $20-30 \%$ of patients with ST-segment elevation myocardial infarction (STEMI) treated with primary $\mathrm{PCl}$ suffer from considerable myocardial injury, which leads to adverse remodeling. In turn, this corresponds with the increased risk of major adverse cardiovascular events [1, 2].

The final area of myocardial infarction is inextricably connected with the occurrence of long-term complications, such as heart failure and malignant ventricular arrhythmias, translating to impaired quality of life and increased mortality. This refers in particular to anterior wall STEMI, which is caused by acute occlusion of the left anterior descending (LAD) artery and confers a large area of necrosis and LV remodeling and further systolic and diastolic dysfunction [3, 4]. The process of LV wall remodeling substantially increases the risk of major adverse cardiovascular events (MACE), including death. Pharmacological management of STEMI in the form of angiotensin-converting enzyme inhibitors (ACEI), $\beta$-blockers and mineralocorticoid receptor antagonists (MRA) leads to the reduction of the extent of pathological LV remodeling. Recently the concept of reverse remodeling was established, which is defined as the decrease of LV end-systolic volume (LVESV) by $\geq 10 \%$ in relation to the baseline value $[5,6]$. Reverse remodeling is thought to be triggered by early myocardial revascularization and adequately tailored pharmacotherapy and conditioned by preserved microvascular flow within the infarction zone [6]. Of note, reverse remodeling was associated with a favorable response to cardiac resynchronization therapy (CRT) and improved prognosis in patients with heart failure [7]. More importantly, reverse remodeling was linked to improved long-term prognosis in patients with acute myocardial infarction [8]. However, its determinants have not been fully understood so far.

\section{Aim}

Accordingly, the aim of the study was to evaluate the prevalence and predictors of the phenomenon of LV reverse remodeling and investigate its association with MACE at 4-year follow-up in patients with anterior wall STEMI treated with primary $\mathrm{PCl}$.

\section{Material and methods}

This prospective observational study was conducted in the First Department of Cardiology, Medical University of Silesia in Katowice and included 40 patients with the first ever acute STEMI of anterior wall with the onset of symptoms within $12 \mathrm{~h}$ preceding hospital admission and acute occlusion of the left anterior descending artery (TIMI 0 flow during initial coronarography in every patient). The patients were admitted between 2011 and 2013. The mandatory inclusion criteria were successful reperfusion with primary $\mathrm{PCI}$ reflected by TIMI 3 coronary flow grade at the end of the procedure and sufficient quality of echocardiographic imaging. Exclusion criteria consisted of: a) former myocardial infarction; b) hypertrophic cardiomyopathy; $c$ ) heart rhythm different than sinus rhythm; d) obesity (body mass index $(\mathrm{BMI})>30 \mathrm{~kg} / \mathrm{m}^{2}$ ); e) contraindications to cardiac magnetic resonance imaging and/or gadolinium use.

All the enrolled patients granted their written informed consent for participation in the study and personal data processing. The study protocol was approved by the local Ethics Committee and the study adhered to the Declaration of Helsinki.

On admission patients with anterior wall STEMI [9] were diligently screened for inclusion and exclusion criteria. Data regarding demographic, clinical, laboratory and electrocardiographic variables were gathered in all the applicable patients. Three-dimensional transthoracic echocardiography (3D-TTE) was performed: at admission, at discharge and at 3-month follow-up. The study population was categorized into: a) patients with reverse remodeling defined as the reduction of left ventricular end systolic volume (LVESV) by $\geq 10 \%$ at 3 -month observation; and $b$ ) patients with confirmed $<10 \%$ reduction or even increase of LVESV at 3-month follow-up.

Additionally, patients underwent cardiac magnetic resonance imaging (CMR) at 3-month follow-up in order to determine the mass of the infarct area relative to total left ventricular mass (LVM). Large myocardial infarction was defined as one covering $\geq 20 \%$ of LVM [10-12].

Following index hospitalization and echocardiographic and CMR check-up at 3 months, patients were subject to 4-year follow-up in order to obtain the rate of combined end-point of MACE defined as: death, urgent coronary revascularization, myocardial infarction and hospitalization due to acute decompensated heart failure. In addition, at 4 years, patients were interviewed to establish current symptomatology according to the New York Heart Association scale (NYHA) and Canadian Cardiovascular Society scale (CCS).

The association between baseline demographic and clinical parameters, as well as the presence of reverse remodeling at 3 months, and MACE rate at 4 years, was assessed. Furthermore, the link between baseline demographic, clinical, electrocardiographic and echocardiographic variables and the presence of reverse remodeling at 3 months was adjudicated.

\section{Electrocardiography}

A series of standard 12-lead electrocardiograms was performed in all patients before $\mathrm{PCl}$ and directly after the procedure so as to assess the maximal ST-segment elevation, as well as the sum of ST-segment elevations in all leads.

\section{Echocardiography}

3D TTE was performed using a volumetric sector transducer (GE Vingmed Ultrasound, Horten, Norway). The probe 
allowed for a real-time evaluation of segments characterized by $30^{\circ}$ of depth and $100^{\circ}$ of width. The stored data were subsequently subject to offline echocardiographic quantification by means of TomTec software (TomTec Imaging Systems, Unterschleissheim, Germany) in order to assess LVESV, left ventricular end-diastolic volume (LVEDV), left ventricular ejection fraction (LVEF) and wall motion score index (WMSI), as well as the presence and severity of mitral valve insufficiency (MVI). The classification of MVI severity was based on vena contracta width (VC): $>7 \mathrm{~mm}-$ severe; 3-7 - $\mathrm{mm}$ moderate; $<3 \mathrm{~mm}$ - mild [13].

Based on the data acquired during discharge TTE, left ventricular speckle tracking imaging (STI) was conducted using the offline analysis Echo-PAC software (PC 6.0.0 GE Medical System). Global longitudinal strain (GLS) of LV was calculated as the arithmetic mean of longitudinal strain of all 16 segments of the LV, while anterior global longitudinal strain (AGLS) was derived from the arithmetic mean of anterior wall segments only $(1-2,7-8,12-16)$.

\section{Cardiac magnetic resonance (CMR)}

The size and mass of the LV infarction were evaluated by means of 1.5 Tesla magnetic resonance scanner at $90 \pm 5$ days. Cardiac magnetic resonance was performed in short axis 2- and 4-chamber view by means of contrast-free fast imaging employing a steady-state acquisition (FIESTA) cine sequence, as well as by a fast gradient recalled echo (FGRE) sequence $10 \mathrm{~min}$ after the administration of gadobenate dimeglumine contrast agent (Multihance; Bracco Inc.) at the dose of $0.1 \mathrm{mmol} / \mathrm{kg}$ in order to obtain late gadolinium enhancement (LGE). Cardiac magnetic resonance slice thickness was $8 \mathrm{~mm}$. The CMR images were acquired during held expiration lasting for about $10 \mathrm{~s}$, following deep inspiration.

The FIESTA cine sequence allowed for evaluation of LVEDV, LVESV and LVEF. The FGRE sequence indicated the sites of $L G E$ in relation to each of the 16 segments of the LV. Subsequently, LV infarction mass and total LVM were calculated using MASS post-processing software (Medis). This semi-automatic method required manual outlining of the border of the endocardium and epicardium (LVM) and the margins of the LGE area (LV infarction mass). Both values were acquired during systole. The relative percentage of LV affected by infarction was derived from the ratio of LV infarct mass and LVM.

\section{Patient management and definitions}

Acute STEMI was diagnosed and treated according to applicable 2012 ESC Guidelines [9]. All the patients were managed invasively and were referred for coronary angiography and primary $\mathrm{PCl}$ of the infarct-related artery (LAD) with drug-eluting stent implantation within $12 \mathrm{~h}$ after onset of symptoms. All the patients received aspirin and clopidogrel loading doses prior to the procedure and unfractionated heparin intraprocedurally. The use of Ilb/ Illa inhibitor was left to the discretion of the operator.

Arterial hypertension was diagnosed if blood pressure exceeded 140/90 $\mathrm{mm} \mathrm{Hg}$ on two separate measurements during index hospitalization or in the event of former hypertension diagnosis or antihypertensive medication use. Diabetes mellitus/impaired fasting glucose/impaired glucose tolerance were analyzed jointly. Diabetes mellitus was diagnosed if fasting blood glucose was > $125 \mathrm{mg} / \mathrm{dl}$ on 2 separate days or if patients received insulin or oral hypoglycemic agents.

\section{Statistical analysis}

Statistical analysis was performed using Statistica 10.0 (StatSoft Poland) software. Continuous variables are expressed as mean and standard deviation (normally distributed) or as median and interquartile range (IQR) (non-normally distributed). The type of distribution was verified using the Shapiro-Wilk test. Qualitative variables are expressed as crude values and percent. Between-group differences for normally distributed quantitative variables were assessed using Student's $t$-test or analysis of variance, and the Mann-Whitney U-test or Kruskal-Wallis test was used for non-normally distributed variables. For qualitative variables, Fisher's exact test was applied. In the univariate Cox analysis reverse remodeling was defined as a dependent variable, whereas independent variables were designated from amongst peri-procedural parameters. Odds ratios (OR) with 95\% confidence intervals (Cls) were calculated. A multivariate stepwise logistic regression model was not implemented on account of the low study count. Univariate Cox analysis was performed to evaluate potential variables affecting the risk of major cardiovascular events (MACE), which was further depicted by a Kaplan-Meier curve. Hazard ratios (HR) with 95\% Cls were subsequently estimated. Kaplan-Meier curves for the different sub-groups were compared using the log-rank test. Throughout the analyses, a $p$-value of $<0.05$ was considered statistically significant.

\section{Results}

Left verticular reverse remodeling at 3-month follow-up was confirmed in 15 (37.5\%) patients. The group with reverse remodeling and the control group did not differ in terms of demographic parameters and baseline cardiovascular risk factors (Table I). Patients with LV reverse remodeling were characterized by significantly lower maximal high-sensitivity troponin T (hs-TnT) concentration, lower sum of all ST-segment elevations before and after $\mathrm{PCl}$ and lower maximal ST-segment elevation after $\mathrm{PCl}$. The presence of $\mathrm{LV}$ reverse remodeling was also associated with lower discharge WMSI and greater AGLS (Table II). Notably, the groups did not differ in terms of discharge LVEF (Table II). 
Table I. Comparison of baseline demographic and clinical characteristics in study and control group

\begin{tabular}{|c|c|c|c|}
\hline Variable & $\begin{array}{c}\text { LV reverse remodeling }(+) \\
(n=15) \\
\text { Mean } \pm \text { SD or } n(\%)\end{array}$ & $\begin{array}{c}\text { LV reverse remodeling (-) } \\
\qquad(n=25) \\
\text { Mean } \pm \text { SD or } n(\%)\end{array}$ & $P$-value \\
\hline Male sex & $11(78.57)$ & $17(70.83)$ & $0.46^{c}$ \\
\hline Age [years] & $55.64 \pm 7.73$ & $61.67 \pm 10.93$ & $0.08^{b}$ \\
\hline Weight [kg] & $79.07 \pm 10.01$ & $76.54 \pm 11.69$ & $0.50^{\mathrm{b}}$ \\
\hline Hospitalization time [days] & $6.21 \pm 0.98$ & $6.79 \pm 1.10$ & $0.24^{a}$ \\
\hline $\begin{array}{l}\text { Time from onset of symptoms to } \\
\text { reperfusion therapy [min] }\end{array}$ & $297.50 \pm 171.85$ & $284.17 \pm 201.64$ & $0.50^{a}$ \\
\hline Arterial hypertension & $13(92.86)$ & $19(79.17)$ & $0.26^{c}$ \\
\hline Dyslipidemia & $8(57.14)$ & $20(83.33)$ & $0.08^{c}$ \\
\hline Diabetes mellitus & $0(0)$ & $4(16.67)$ & $0.14^{c}$ \\
\hline Cigarette smoking & $9(64.29)$ & $13(54.17)$ & $0.40^{c}$ \\
\hline AKI in anamnesis & $0(0)$ & $1(4.17)$ & $0.63^{c}$ \\
\hline Stroke/TIA in anamnesis & $0(0)$ & $2(8.33)$ & $0.39^{c}$ \\
\hline
\end{tabular}

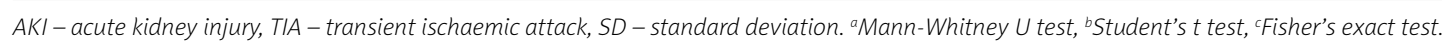

Table II. Comparison of laboratory, electrocardiographic and imaging variables in study and control group

\begin{tabular}{|c|c|c|c|}
\hline Variable & $\begin{array}{c}\text { LV reverse remodeling }(+) \\
(n=15) \\
\text { Mean } \pm \text { SD or } n(\%)\end{array}$ & $\begin{array}{c}\text { LV reverse remodeling }(-) \\
(n=25) \\
\text { Mean } \pm \text { SD or } n(\%)\end{array}$ & $P$-value \\
\hline Multi-vessel CAD & $7(50)$ & $12(50)$ & $1.00^{c}$ \\
\hline Proximal LAD occlusion & $9(64.29)$ & $13(54.17)$ & $0.40^{c}$ \\
\hline GP IIb/IIla inhibitor use & $10(71.43)$ & $18(75)$ & $0.55^{\mathrm{c}}$ \\
\hline Serum creatinine concentration [mg/dl] & $0.88 \pm 0.28$ & $0.83 \pm 0.18$ & $0.71^{a}$ \\
\hline Maximal hs-TnT concentration [ng/ml] & $5.70 \pm 5.24$ & $14.89 \pm 10.41$ & $<0.01^{a}$ \\
\hline Maximal CK-MB concentration [U/I] & $116.00 \pm 135.01$ & $252.55 \pm 238.27$ & $0.08^{\mathrm{a}}$ \\
\hline Sum of ST-segment elevations before PCI [mm] & $9.46 \pm 5.51$ & $16.08 \pm 8.62$ & $0.02^{\mathrm{a}}$ \\
\hline Max. ST-segment elevation before PCI [mm] & $3.54 \pm 1.93$ & $4.33 \pm 1.95$ & $0.23^{b}$ \\
\hline Sum of ST-segment elevations after PCI [mm] & $3.75 \pm 2.56$ & $8.52 \pm 6.52$ & $<0.01^{a}$ \\
\hline Max. ST-segment elevation after PCI [mm] & $1.46 \pm 0.93$ & $2.54 \pm 1.44$ & $0.01^{a}$ \\
\hline Mitral valve insufficiency & $2(14.29)$ & $8(40)$ & $0.11^{c}$ \\
\hline Vena contracta [mm] & $0.21 \pm 0.58$ & $1.14 \pm 1.75$ & $0.14^{\mathrm{a}}$ \\
\hline LVEDV - 3D-TTE [ml] & $112.99 \pm 36.10$ & $100.79 \pm 23.41$ & $0.21^{\mathrm{b}}$ \\
\hline LVESV - 3D-TTE [ml] & $60.42 \pm 24.88$ & $52.38 \pm 14.16$ & $0.78^{\mathrm{a}}$ \\
\hline LVESV - 3D-TTE at 3 months [ml] & $43.52 \pm 14.27$ & $69.48 \pm 29.06$ & $<0.01^{a}$ \\
\hline SV - 3D-TTE [ml] & $52.57 \pm 18.56$ & $48.39 \pm 14.69$ & $0.45^{b}$ \\
\hline LVEF - 3D-TTE [\%] & $46.66 \pm 9.34$ & $47.91 \pm 9.05$ & $0.69^{b}$ \\
\hline Wall motion score index (WMSI) & $1.23 \pm 0.18$ & $1.39 \pm 0.18$ & $0.02^{\mathrm{a}}$ \\
\hline Global longitudinal strain (GLS) [\%] & $-14.06 \pm 4.48$ & $-11.65 \pm 4.67$ & $0.13^{b}$ \\
\hline Anterior global longitudinal strain (AGLS) [\%] & $-12.61 \pm 6.33$ & $-7.89 \pm 5.90$ & $0.03 b$ \\
\hline LVEDV - CMR at 3 months [ml] & $101.97 \pm 24.74$ & $121.41 \pm 33.21$ & $0.11^{a}$ \\
\hline LVESV - CMR at 3 months [ml] & $43.52 \pm 14.27$ & $69.48 \pm 29.06$ & $<0.01^{a}$ \\
\hline SV - CMR at 3 months [ml] & $58.75 \pm 16.41$ & $51.93 \pm 16.90$ & $0.19^{a}$ \\
\hline LVEF - CMR at 3 months [\%] & $57.42 \pm 7.86$ & $44.30 \pm 12.78$ & $<0.01^{a}$ \\
\hline LVM [g] & $144.57 \pm 42.36$ & $145.90 \pm 34.89$ & $0.92^{\mathrm{a}}$ \\
\hline LV infarction mass [g] & $32.89 \pm 35.97$ & $41.34 \pm 23.98$ & $0.21^{a}$ \\
\hline Large myocardial infarct $>20 \%$ of LVM & $6(42.86)$ & $17(70.83)$ & $0.09^{c}$ \\
\hline
\end{tabular}

CAD - coronary artery disease, CMR - cardiac magnetic resonance, GP - glycoprotein, LAD - left anterior descending artery, LVEDV - left ventricular end-diastolic volume, LVEF - left ventricular ejection fraction, LVESV - left ventricular end-systolic volume, SV - stroke volume, 3D-TTE - 3-dimensional transthoracic echocardiography, LVM - left ventricular mass, $P C l$ - percutaneous coronary interventions, CK-MB - creatine kinase MB fraction, hs-TnT-high-sensitivity troponin T, SD - standard deviation, ${ }^{a}$ Mann-Whitney $U$ test, ${ }^{b}$ Student's t test, ${ }^{c}$ Fisher's exact test. 
Following 3-month follow-up, patients with LV reverse remodeling (3D-TTE) distinguished themselves with greater LVEF, and lower LVESV evaluated by simultaneous CMR (Table II). A non-significantly lower rate of large myocardial infarction ( $>20 \%$ of LVM) was observed in the group with reverse remodeling (Table II).

\section{Analysis of correlation}

The change between discharge and 3-month LVESV assessed in 3D-TTE ( $\triangle$ LVESV) positively correlated with maximal hs-TnT concentration, the severity of MVI during index hospitalization, the sum of ST-segment elevations before and after $\mathrm{PCl}$, the maximal ST-segment elevation after PCI and both GLS and AGLS (Table III). Conversely, $\triangle$ LVESV negatively correlated with LVEF assessed at 3-month follow-up by means of reference method in the form of CMR (Table III).

\section{Univariate analysis of the predictors of LV reverse remodeling}

The presence of LV reverse remodeling at 3-month follow-up was accurately heralded by lower hs-TnT levels, lower sum of ST-segment elevations before and after $\mathrm{PCl}$, and lower maximal ST-segment elevation after $\mathrm{PCl}$ (Table IV). Among echocardiographic parameters, lower WMSI and more negative anterior global longitudinal strain (AGSL) (mean longitudinal strain in the segments supplied by LAD) were both associated with LV reverse remodeling in 3D-TTE (Table IV).

\section{Prospective follow-up}

All the patients enrolled in the study were subject to follow-up for a median of 3.4 years. In total, nine endpoints were reported, including 2 deaths, 4 episodes of acute coronary syndrome requiring urgent revascularization and 3 hospital admissions due to acute decompensated heart failure. Of note, all the endpoints occurred in the study group without LV reverse remodeling at 3-month follow-up (Figure 1).

Univariate Cox analysis revealed that composite endpoint (MACE) was associated with higher baseline NYHA class, maximal ST-segment elevation after $\mathrm{PCl}$ and the sum of ST-segment elevations before and after PCI. MACE occurrence was also predicted by lower discharge LVEF, higher discharge WMSI and less negative GLS and AGLS (Table V). Furthermore, the onset of MACE was also associated with the growing severity of $M V I$ reflected by higher VC, but not the mere presence of MVI itself (Table V). In the analyzed population, MVI was demonstrated in 11 patients, including 9 cases of mild MVI and 2 cases of moderate $\mathrm{MVI}(\mathrm{VC}=5$ and $\mathrm{VC}=6 \mathrm{~mm})$. The presence of $\mathrm{LV}$ reverse remodeling at 3-month follow-up was not associated with MACE in 4-year observation.

The comparison of Kaplan-Meier survival curves for the study population depending on the presence of 3-month LV reverse remodeling is denoted in Figure 1. Based on the log-rank test, a non-significantly more favorable prognosis in the LV reverse modeling group was observed (log rank $p=0.07$ ).

Table III. Analysis of correlation between different clinical variables and the change of 3-month left ventricular end-systolic velocity ( $\triangle$ LVESV - 3D-TTE) in relation to baseline value as assessed in 3D-TTE

\begin{tabular}{lcc}
\hline LVESV vs. & Spearman $\boldsymbol{R}$ & $\boldsymbol{P}$-value \\
\hline $\begin{array}{l}\text { Maximal hs-TnT } \\
\text { concentration }\end{array}$ & 0.53 & $<0.05$ \\
\hline $\begin{array}{l}\text { Sum of ST-segment elevations } \\
\text { before PCl }\end{array}$ & 0.40 & 0.01 \\
\hline $\begin{array}{l}\text { Sum of ST-segment elevations } \\
\text { after PCl }\end{array}$ & 0.46 & $<0.05$ \\
\hline $\begin{array}{l}\text { Max. ST-segment elevation } \\
\text { after PCl }\end{array}$ & 0.40 & 0.01 \\
\hline $\begin{array}{l}\text { MVI vena contracta } \\
\text { Global longitudinal strain }\end{array}$ & 0.35 & 0.03 \\
\hline $\begin{array}{l}\text { Anterior global longitudinal } \\
\text { strain }\end{array}$ & 0.40 & 0.02 \\
\hline \begin{tabular}{l} 
LVEF - CMR at 3 months \\
\hline
\end{tabular} & -0.63 & 0.01 \\
\hline
\end{tabular}

$\triangle L V E S V$ - change of ESV between baseline and follow-up at 3 months, LVEFleft ventricular ejection fraction, hs-TnT - high-sensitivity troponin $T, P C l-p e r-$ cutaneous coronary intervention, MVI - mitral valve insufficiency, Max. - maximal, CMR - cardiac magnetic resonance imaging.

Table IV. Univariate analysis of different predictors of left ventricular reverse remodeling

\begin{tabular}{|c|c|c|c|}
\hline Variable & OR & $95 \% \mathrm{Cl}$ & $P$-value \\
\hline Age [per 1 year] & 0.94 & $0.87-1.01$ & 0.09 \\
\hline $\begin{array}{l}\text { Hospitalization time } \\
\text { [per } 1 \text { day] }\end{array}$ & 0.59 & $0.29-1.1$ & 0.13 \\
\hline Hyperlipidemia & 0.27 & $0.056-1.27$ & 0.09 \\
\hline $\begin{array}{l}\text { Maximal hs-TnT } \\
\text { concentration [per } 1 \mathrm{ng} / \mathrm{ml}]\end{array}$ & 0.86 & $0.75-0.98$ & 0.02 \\
\hline $\begin{array}{l}\text { Maximal CK-MB } \\
\text { concentration [per } 1 \mathrm{U} / \mathrm{l}]\end{array}$ & 0.99 & $0.99-1.0$ & 0.098 \\
\hline $\begin{array}{l}\text { Sum of ST-segment } \\
\text { elevations before } \mathrm{PCl} \\
\text { [per } 1 \mathrm{~mm} \text { ] }\end{array}$ & 0.87 & $0.77-0.99$ & 0.03 \\
\hline $\begin{array}{l}\text { Sum of ST-segment } \\
\text { elevations after PCl } \\
\text { [per } 1 \mathrm{~mm}]\end{array}$ & 0.69 & $0.51-0.93$ & 0.02 \\
\hline $\begin{array}{l}\text { Max. ST-segment elevation } \\
\text { after } \mathrm{PCI}[\text { per } 1 \mathrm{~mm} \text { ] }\end{array}$ & 0.40 & 0.17-0.93 & 0.03 \\
\hline $\begin{array}{l}\text { Wall motion score index } \\
\text { [per } 1 \text { unit] }\end{array}$ & 0.01 & $0.00-0.63$ & 0.03 \\
\hline $\begin{array}{l}\text { Anterior global longitudinal } \\
\text { strain [per } 1 \text { unit] }\end{array}$ & 0.88 & $0.78-1.00$ & 0.045 \\
\hline $\begin{array}{l}\text { Global longitudinal strain } \\
\text { [per } 1 \text { unit] }\end{array}$ & 0.89 & $0.76-1.04$ & 0.15 \\
\hline
\end{tabular}

$O R$ - odds ratio, $95 \% \mathrm{Cl}$ - 95\% confidence interval, CK-MB - creatine kinase $M B$ fraction, hs-TnT-high-sensitivity troponin T. 


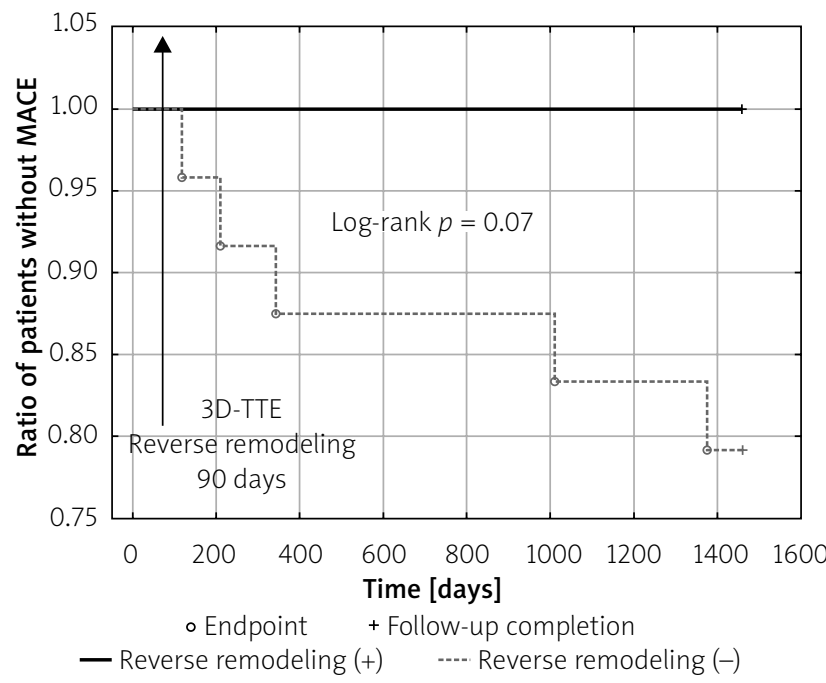

Figure 1. Kaplan-Meier curve of major adverse cardiovascular events depending on the presence of reverse left ventricular remodeling in 4-year observation

MACE - major adverse cardiovascular events, $\mathrm{MI}$ - myocardial infarction, 3D-TTE - 3-dimensional transthoracic echocardiography, arrow - point of 3D-TTE assessment of $L V$ reverse remodeling at 3-month follow-up.

\section{Discussion}

The current study concerned a specific cohort of patients with anterior wall STEMI submitted to primary $\mathrm{PCl}$, who experienced a considerable myocardial injury at 3 months after the procedure, reflected by a predominantly large area ( $>20 \%$ of LVM) of postinfarction myocardial scar ( $n=23,57.5 \%)$. The higher than expected rate of patients with adverse LV remodeling, despite the guideline-tailored approach to management, is presumably linked to prolonged time from onset of symptoms to reperfusion therapy (mean: $294 \mathrm{~min}$ ). In the present study, the authors focused on the phenomenon of LV reverse remodeling at 3 months after anterior wall STEMI treated with primary $\mathrm{PCl}[14,15]$. This process has previously been documented in heart failure patients subject to CRT therapy or following surgical coronary revascularization [14, 15]. In the analyzed population, LV reverse remodeling was confirmed in roughly $40 \%$ of patients. The development of this favorable myocardial remodeling translates into better functional capacity and less pronounced symptoms of heart failure, as well as the reduced risk of adverse cardiovascular events. It is broadly known that adverse LV remodeling connected with the area of myocardial infarction is associated with higher risk of adverse cardiovascular events [16], while LV reverse remodeling accounts for the opposite effect on cardiovascular risk [17]. The investigation into the significance of positive LV reverse remodeling is inherent in contemporary cardiology. Parallel to reverse remodeling, a different echocardiographic parameter in the form of
Table V. Univariate Cox analysis of different predictors of composite endpoint (death, myocardial infarction, urgent coronary revascularization, heart failure hospitalization)

\begin{tabular}{|c|c|c|c|}
\hline Variable & HR & $95 \% \mathrm{Cl}$ & $P$-value \\
\hline Age [per 1 year] & 1.10 & $0.99-1.22$ & 0.07 \\
\hline Arterial hypertension & 0.69 & $0.08-6.18$ & 0.74 \\
\hline Diabetes mellitus & 1.92 & $0.21-17.16$ & 0.56 \\
\hline Cigarette smoking & 1.12 & $0.19-6.68$ & 0.90 \\
\hline $\begin{array}{l}\text { Time of onset of symptoms to } \\
\text { reperfusion therapy [per } 1 \mathrm{~min} \text { ] }\end{array}$ & 0.99 & $0.98-1.00$ & 0.09 \\
\hline Multi-vessel CAD & 4.47 & $0.50-40.00$ & 0.18 \\
\hline Proximal LAD occlusion & 1.14 & $0.19-6.82$ & 0.89 \\
\hline GP IIb/IIla antagonist use & 1.51 & $0.17-13.49$ & 0.71 \\
\hline $\begin{array}{l}\text { Serum creatinine concentration } \\
\text { [per } 1 \mathrm{mg} / \mathrm{dl}]\end{array}$ & 0.00 & $0.00-2.62$ & 0.09 \\
\hline $\begin{array}{l}\text { Maximal hs-TnT concentration } \\
{[\text { per } 1 \mathrm{ng} / \mathrm{ml}]}\end{array}$ & 1.06 & $0.98-1.15$ & 0.15 \\
\hline $\begin{array}{l}\text { Maximal CK-MB concentration } \\
{[\text { per } 1 \mathrm{U} / \mathrm{l}]}\end{array}$ & 1.00 & $1.00-1.01$ & 0.30 \\
\hline $\begin{array}{l}\text { NYHA class at admission } \\
\text { [per } 1 \text { class] }\end{array}$ & 37.73 & $2.38-597.29$ & 0.01 \\
\hline $\begin{array}{l}\text { NYHA class at discharge } \\
\text { [per } 1 \text { class] }\end{array}$ & 1.75 & $0.56-5.47$ & 0.33 \\
\hline $\begin{array}{l}\text { CCS class at discharge } \\
\text { [per } 1 \text { class] }\end{array}$ & 1.52 & $0.52-4.43$ & 0.44 \\
\hline $\begin{array}{l}\text { Sum of ST-segment elevations } \\
\text { before PCI [per } 1 \mathrm{~mm} \text { ] }\end{array}$ & 1.12 & $1.01-1.23$ & 0.03 \\
\hline $\begin{array}{l}\text { Sum of ST-segment elevations } \\
\text { after PCI [per } 1 \mathrm{~mm} \text { ] }\end{array}$ & 1.12 & $1.02-1.22$ & 0.02 \\
\hline $\begin{array}{l}\text { Max. ST-segment elevation } \\
\text { before PCI [per } 1 \mathrm{~mm} \text { ] }\end{array}$ & 1.74 & $1.03-2.92$ & 0.04 \\
\hline $\begin{array}{l}\text { Max. ST-segment elevation after } \\
\text { PCl [per } 1 \mathrm{~mm} \text { ] }\end{array}$ & 1.71 & $1.04-2.81$ & 0.04 \\
\hline Presence of MVI & 5.73 & $0.84-39.16$ & 0.08 \\
\hline MVI - vena contracta [per $1 \mathrm{~mm}$ ] & 1.56 & $1.07-2.27$ & 0.02 \\
\hline LVEDV - 3D-TTE [per $1 \mathrm{ml}]$ & 0.99 & $0.96-1.03$ & 0.65 \\
\hline LVESV - 3D-TTE [per $1 \mathrm{ml}]$ & 1.01 & $0.97-1.05$ & 0.59 \\
\hline SV - 3D-TTE [per $1 \mathrm{ml}]$ & 0.95 & $0.88-1.02$ & 0.14 \\
\hline LVEF - 3D-TTE [per 1\%] & 0.87 & $0.78-0.98$ & 0.02 \\
\hline $\begin{array}{l}\text { Wall motion score index } \\
\text { [per } 1 \text { unit] }\end{array}$ & 17064.2 & $\begin{array}{c}16.00- \\
18198120\end{array}$ & 0.01 \\
\hline $\begin{array}{l}\text { Global longitudinal strain } \\
\text { [per } 1 \text { unit] }\end{array}$ & 1.32 & $1.00-1.73$ & 0.05 \\
\hline $\begin{array}{l}\text { Anterior global longitudinal } \\
\text { strain [per } 1 \text { unit] }\end{array}$ & 1.29 & $1.02-1.63$ & 0.04 \\
\hline LV reverse remodeling & 0.004 & $\begin{array}{l}<0.001- \\
68717.43\end{array}$ & 0.51 \\
\hline
\end{tabular}

$H R$ - hazard ratio, $\mathrm{Cl}$ - confidence interval, $C A D$ - coronary artery disease, GP - glycoprotein, LAD - left anterior descending artery, LVEDV - left ventricular end-diastolic volume, LVEF - left ventricular ejection fraction, LVESV - left ventricular end-systolic volume, MVI - mitral valve insufficiency, SV - stroke volume, 3D-TTE - 3-dimensional transthoracic echocardiography, $P C l$ - percutaneous coronary interventions, CK-MB - creatine kinase $M B$ fraction, hs-TnT - high-sensitivity troponin T, SD - standard deviation. 
LVEF assessed after acute myocardial infarction is used for the identification of patients suitable for placement of an implantable-cardioverter defibrillator (ICD) for the prevention of sudden cardiac death [18]. As certain patients experience mid- and long-term improvement of LV systolic function and positive ventricular remodeling following myocardial infarction, patients are not referred for ICD/CRT implantation directly after acute coronary syndrome [18]. Thus, it is recommended to evaluate LVEF and $\mathrm{LV}$ reverse remodeling after at least 3 months of optimal medical therapy in order to identify patients who could benefit from ICD/CRT implantation for primary prevention of sudden cardiac death [18].

Left ventricular reverse remodeling also remains one of the beneficial signs of CRT pacing. A large body of evidence suggests that the volume parameters of LV decrease in response to CRT pacing, while device deactivation leads to a gradual increase of LV volume [19]. The development of reverse remodeling is also conditioned by optimal medical therapy, as both ACEI and $\beta$-blockers facilitate reduction of LVESV [20-22]. Also, the use of an LV assist device (LVAD) was shown to cause a reduction of LV volume [23].

The majority of former studies analyzed the role of LV reverse remodeling in patients with heart failure or cardiomyopathies, whereas its significance in patients with STEMI has not been extensively investigated. One of the few studies in the field, the AMICI trial [8], delivered evidence for the significance of ST-segment elevation reduction after $\mathrm{PCl}$ as a crucial determinant of LV reverse remodeling [8]. Unlike in the present report, the presence of reverse remodeling was verified not at 3 months, but at 6 months after the incident [8]. Left ventricular reverse remodeling was defined in a similar way to the current study and occurred in $39 \%$ of patients (vs. $37.5 \%$ in our study).

In the Japanese study by Morishita et al. [24] LV reverse modeling was demonstrated in $52 \%$ of patients, despite the strict criterion of $\geq 15 \%$ LVESV reduction [24]. The difference between the present study and the cited report may be underlined by the longer (6-month) observation time in the latter study [24]. This discrepancy may well be related to the significantly shorter pain to balloon time (1.0-1.8 vs. 4.7-4.9 h), which also accounted for higher LVEF values in the Japanese study [24]. It is widely accepted that prolonged coronary revascularization leads to impaired prognosis; hence time to balloon should not exceed 90 min [25]. It was shown that any reduction of time to reperfusion translates into improvement of LV function assessed by means of CMR [26].

The determinants of LV reverse remodeling corroborated in the current study are in line with the acknowledged parameters formerly described in the literature. Lower concentration of cardiac troponin [27, 28], as well as several electrocardiographic [29] and echocardio- graphic parameters [30], proved to be predictors of LV remodeling in the present study.

The study provided evidence to support the notion that speckle tracking-derived mean longitudinal strain of anterior wall segments (AGLS) supplied by the LAD constitutes a potent predictor of favorable LV remodeling. In the study by Spinelli et al., speckle tracking allowed for precise prediction of favorable change of LV anatomy by estimation of LV torsional strain [5]. In addition, the research by Mitro et al. showed that LV strain rate heralded the response to CRT [31]. The predictive significance of speckle tracking imaging was also confirmed in the case of reverse left atrial remodeling after mitral valve surgery [32].

The present research constitutes a unique approach at evaluation of the use of LV longitudinal strain (GLS and AGLS) for the prediction of LV reverse remodeling after acute myocardial infarction. Although AGLS remained a predictor of LV reverse remodeling, GLS did not prove to be useful for this purpose, which may be linked to increased regional contractility of the contralateral (basal segments) of LV compensating for the impaired contractility within the area supplied by the infarct-related artery.

In the analyzed population, only nine endpoints were reported. All the endpoints occurred in the group without LV reverse remodeling and with a large area of myocardial necrosis. The considerably low amount of endpoints may be due to adequate pharmacotherapy in adherence to ESC guidelines [9]. This favorable pharmacological effect is augmented by a large number of patients with preserved LV systolic function at discharge. This fact is considered to be a potent predictor of favorable prognosis after coronary incidents. Moreover, our population was characterized by relatively low prevalence of diabetes mellitus (12.5\%), which has a deleterious effect on prognosis and postinfarction scarring area based on echocardiographic and CMR imaging [33]. According to previous studies, diabetes mellitus is present in $21-25 \%$ [34] or even $35 \%$ of patients with a STEMI diagnosis [25]. For this reason, the mortality rate in 4-year observation was much lower than the average 1-year mortality in contemporary STEMI registries [24, 35, 36].

Yet another aspect of our study is the prognostic significance of AGLS and GLS with respect to the 4-year composite endpoint. According to a recent study by Milewska et al., LV GLS exceeding the threshold of $>-12.8 \%$ was associated with adverse cardiovascular events, irrespective of LVEF value [37]. According to a recent systematic review concerning the role of speckle tracking in myocardial infarction of different locations, GLS exhibited predictive power regarding both reverse remodeling and MACE [38].

Our study also corroborated the role of classic electrocardiographic parameters in the prediction of adverse cardiovascular events in a population of patients with STEMI. These findings are in accordance with the former 
observations concerning the relationship between maximal pre-PCI ST-segment elevation and the area of necrosis [39], as well as between post-procedural regression of ST-segment elevation and the success of coronary reperfusion therapy [40].

Surprisingly, the presence of LV reverse remodeling at 3-month follow-up was not associated with the long-term onset of MACE. The authors presume that this finding may be explained by the very narrow inclusion criteria with first ever anterior wall STEMI patients only and relatively high discharge LVEF and echocardiographic volume indices resembling physiological values. For this reason, $\mathrm{LV}$ reverse remodeling pertained to a population at relatively low risk of MACE onset.

The univariate Cox analysis yielded negative results concerning prognostic significance of $\mathrm{MVI}$, time from onset of symptoms to reperfusion or presence of diabetes mellitus (Table V).

The limited prognostic significance of MVI may be explained by predominantly mild MVI severity and the lack of severe MVI in the study population. Based on the literature, MVI severity corresponds with impaired outcome and predicts adverse LV remodeling [39]. However, the significance of $\mathrm{MVI}$ is pronounced, providing that $\mathrm{MVI}$ is predominantly of moderate severity.

Last but no least, it was previously proven that presence of LV reverse remodeling corresponds with cardiovascular event-free survival in 2-year observation [8], as well as with long-term heart failure-free survival [6]. This intrinsic finding was somewhat recapitulated in our current manuscript, as the survival curves of both groups non-significantly differed in terms of composite endpoint rate in favor of patients with LV reverse remodeling (Figure 1 ; log-rank $p=0.07$ ).

\section{Study limitations}

The results of the study should be interpreted with caution on account of the low study count related to the specific and narrow inclusion criteria of first ever myocardial infarction limited only to anterior wall localization. This is the reason that the value of our outcome may be limited. Since the majority of study participants were men (75\%), the effect of sex could have modified the study results. According to contemporary data, the proportion of women in the population of patients with myocardial infarction is 30-34\% [41, 42]. The low amount of end-points represents a considerable limitation, which is presumably caused by the high extent of preserved myocardium following successful PCl. Yet another shortcoming of the study is the intentional exclusion of certain myocardial segments during 3D-TTE post-processing due to poor visualization, which could theoretically have altered the study results. The overall proportion of segments excluded from analysis was $5 \%$, which is comparable to other studies in the field [43].

\section{Conclusions}

The rate of $L V$ reverse remodeling in patients with the first ever anterior STEMI treated with primary $\mathrm{PCI}$ is high. The development of LV reverse remodeling at 3 months was predicted by lower hs-TnT values, lower value of the sum of ST-segment elevations before and after PCI, lower maximal ST-segment elevations after $\mathrm{PCl}$, lower WMSI and more negative longitudinal strain in the area supplied by the infarct-related artery. LV reverse remodeling was not associated with the endpoints in 4-year observation.

\section{Conflict of interest}

The authors declare no conflict of interest.

\section{References}

1. Wita K, Filipecki A, Szydło K, et al. Prediction of long-term outcome after primary percutaneous coronary intervention for acute anterior myocardial infarction. Kardiol Pol 2010; 68: 393-400.

2. Bolognese L, Neskovic AN, Parodi G, et al. Left ventricular remodeling after primary coronary angioplasty: patterns of left ventricular dilation and long-term prognostic implications. Circulation 2002; 106: 2351-7.

3. Sciagrà R, Imperiale A, Antoniucci D, et al. Relationship of infarct size and severity versus left ventricular ejection fraction and volumes obtained from $99 \mathrm{mTc}$-sestamibi gated single-photon emission computed tomography in patients treated with primary percutaneous coronary intervention. Eur J Nucl Med Mol Imaging 2004; 31: 969-74.

4. Maskali F, Franken PR, Poussier S, et al. Initial infarct size predicts subsequent cardiac remodeling in the rat infarct model: an in vivo serial pinhole gated SPECT study. J Nucl Med 2006; 47: 337-44.

5. Spinelli L, Morisco C, di Panzillo E, et al. Reverse left ventricular remodeling after acute myocardial infarction: the prognostic impact of left ventricular global torsion. Int J Cardiovasc Imaging 2013; 29: 787-95.

6. Carrabba N, Parodi G, Valenti R, et al. Prognostic value of reverse left ventricular remodeling after primary angioplasty for STEMI. Atherosclerosis 2012; 222: 123-8.

7. Chung ES, Leon AR, Tavazzi L, et al. Results of the predictors of response to CRT (PROSPECT) trial. Circulation 2008; 117: 2608-16.

8. Funaro S, La Torre G, Madonna M, et al. Incidence, determinants, and prognostic value of reverse left ventricular remodelling after primary percutaneous coronary intervention: results of the Acute Myocardial Infarction Contrast Imaging (AMICI) multicenter study. Eur Heart J 2009; 30: 566-75.

9. Task Force on the management of ST-segment elevation acute myocardial infarction of the European Society of Cardiology (ESC), Steg PG, James SK, Atar D, et al. ESC Guidelines for the management of acute myocardial infarction in patients presenting with ST-segment elevation. Eur Heart J 2012; 33: 2569-619.

10. Sjøli B, Ørn S, Grenne B, et al. Comparison of left ventricular ejection fraction and left ventricular global strain as determinants of infarct size in patients with acute myocardial infarction. J Am Soc Echocardiogr 2009; 22: 1232-8.

11. Larose E, Rodés-Cabau J, Pibarot P, et al. Predicting late myocardial recovery and outcomes in the early hours of ST-segment 
elevation myocardial infarction. Traditional measures compared with microvascular obstruction, salvaged myocardium, and necrosis characteristics by cardiovascular magnetic resonance. J Am Coll Cardiol 2010; 55: 2459-69.

12. Pride YB, Giuseffi JL, Mohanavelu S, et al. Relation between infarct size in ST-segment elevation myocardial infarction treated successfully by percutaneous coronary intervention and left ventricular ejection fraction three months after the infarct. Am J Cardiol 2010; 106: 635-40.

13. Zoghbi WA, Enriquez-Sarano M, Foster E, et al. Recommendations for evaluation of the severity of native valvular regurgitation with two-dimensional and Doppler echocardiography. J Am Soc Echocardiogr 2003; 16: 777-802.

14. Łoboz-Grudzień K, Kowalska A, Brzezińska B, et al. Early predictors of adverse left ventricular remodelling after myocardial infarction treated by primary angioplasty. Cardiol J 2007; 14: 238-45.

15. Wita K, Berger-Kucza A, Filipecki A, et al. Predictive value of ischemic mitral regurgitation during the acute phase of ST elevation myocardial infarction treated with primary coronary intervention for left ventricular remodeling in long-term follow-up. Coron Artery Dis 2010; 21: 325-9.

16. Nguyen TL, Phan J, Hogan J Adverse diastolic remodeling after reperfused ST-elevation myocardial infarction: an important prognostic indicator. Am Heart J 2016; 180: 117-27.

17. Solomon SD, Skali H, Anavekar NS, et al. Changes in ventricular size and function in patients treated with valsartan, captopril, or both after myocardial infarction. Circulation 2005; 111: 3411-9.

18. Ponikowski P, Voors AA, Anker SD, et al. 2016 ESC Guidelines for the diagnosis and treatment of acute and chronic heart failure: The Task Force for the diagnosis and treatment of acute and chronic heart failure of the European Society of Cardiology (ESC). Developed with the special contribution of the Heart Failure Association (HFA) of the ESC. Eur J Heart Fail 2016; 18: 891-975.

19. Yu CM, Chau E, Sanderson JE, et al. Tissue Doppler echocardiographic evidence for reverse remodeling and improved synchronicity by simultaneously delaying regional contraction after biventricular pacing therapy in heart failure. Circulation 2002; 105: 438-45.

20. Khattar RS, Senior R, Soman P, et al. Regression of left ventricular remodeling in chronic heart failure: comparative and combined effects of captopril and carvedilol. Am Heart J 2001; 142: 704-13.

21. Sharpe N, Smith H, Murphey J, et al. Early prevention of left ventricular dysfunction after myocardial infarction with angiotensin converting enzyme inhibition. Lancet 1991; 337: 872-6.

22. Hall SA, Cigarroa CG, Marcoux L, et al. Time course of improvementin left ventricular function, mass and geometry in patients with congestive heart failure treated with beta-adrenergic blockade. J Am Coll Cardiol 1995; 25: 1154-61.

23. Zafeiridis A, Jeevanandam V, Houser SR, et al. Regression of cellular hypertrophy after left ventricular assist device support. Circulation 1998; 98: 656-62.

24. Morishita T, Uzui H, Mitsuke $\mathrm{Y}$, et al. Predictive utility of the changes in matrix metalloproteinase- 2 in the early phase for left ventricular reverse remodeling after an acute myocardial infarction. J Am Heart Assoc 2015; 4: e001359.

25. Windecker S, Kolh P, Alfonso F, et al. 2014 ESC/EACTS guidelines on myocardial revascularization. Rev Esp Cardiol (Engl Ed) 2015; 68: 144 .
26. Ortiz-Pérez JT, Betriu A, Lee DC, et al. Angiographic and magnetic resonance imaging evaluation of in-hospital delay in primary percutaneous intervention delivery on myocardial salvage. Am J Cardiol 2010; 106: 924-30.

27. Chia S, Senatore F, Raffel OC, et al. Utility of cardiac biomarkers in predicting infarct size, left ventricular function, and clinical outcome after primary percutaneous coronary intervention for ST-segment elevation myocardial infarction. JACC CardiovasC Interv 2008; 1: 415-23.

28. Hallén J, Jensen JK, Buser P, et al. Relation of cardiac troponin I and microvascular obstruction following ST-elevation myocardial infarction. Acute Card Care 2011; 13: 48-51.

29. Haeck JD, Verouden NJ, Kuijt WJ, et al. Impact of early, late, and no ST-segment resolution measured by continuous ST Holter monitoring on left ventricular ejection fraction and infarct size as determined by cardiovascular magnetic resonance imaging. J Electrocardiol 2011; 44: 36-41.

30. Nicolosi GL, Golcea S, Ceconi C, et al. PREAMI Investigators. Effects of perindopril on cardiac remodelling and prognostic value of pre-discharge quantitative echocardiographic parameters in elderly patients after acute myocardial infarction: the PREAMI echo sub-study. Eur Heart J 2009; 30: 1656-65.

31. Mitro P, Murin P, Valocik G, Simurda M Regional myocardial contractile reserve assessed by strain echocardiography and the response to cardiac resynchronization therapy. Cardiol J 2014; 21: 524-31.

32. Candan O, Ozdemir N, Aung SM, et al. Atrial longitudinal strain parameters predict left atrial reverse remodeling after mitral valve surgery: a speckle tracking echocardiography study. Int J Cardiovasc Imaging 2014; 30: 1049-56.

33. Mather AN, Crean A, Abidin N, et al. Relationship of dysglycemia to acute myocardial infarct size and cardiovascular outcome as determined by cardiovascular magnetic resonance. J Cardiovasc Magn Reson 2010; 12: 61.

34. Poloński L, Gąsior M, Gierlotka M, et al. What has changed in the treatment of ST-segment elevation myocardial infarction in Poland in 2003-2009? Data from the Polish Registry of Acute Coronary Syndromes (PL-ACS). Kardiol Pol 2011; 69: 1109-18.

35. Lawesson SS, Alfredsson J, Fredrikson M, Swahn E. Time trends in STEMI--improved treatment and outcome but still a gender gap: a prospective observational cohort study from the SWEDEHEART registry. BMJ Open 2012; 2: e000726.

36. Gale CP, Allan V, Cattle BA, et al. Trends in hospital treatments, including revascularisation, following acute myocardial infarction, 2003-2010: a multilevel and relative survival analysis for the National Institute for Cardiovascular Outcomes Research (NICOR). Heart 2014; 100: 582-9.

37. Milewska A, Minczykowski A, Krauze T, et al. Prognosis after acute coronary syndrome in relation with ventricular-arterial coupling and left ventricular strain. Int J Cardiol 2016; 220: 343-8.

38. Shetye A, Nazir SA, Squire IB, McCann GP. Global myocardial strain assessment by different imaging modalities to predict outcomes after ST-elevation myocardial infarction: a systematic review. World J Cardiol 2015; 7: 948-60.

39. Lønborg J, Holmvang L, Kelbæk H, et al. ST-segment resolution and clinical outcome with ischemic postconditioning and comparison to magnetic resonance. Am Heart J 2010; 160: 1085-91.

40. de Andrade PB, Rinaldi FS, Bergonso MH, et al. ST-segment resolution after primary percutaneous coronary intervention: characteristics, predictors of failure, and impact on mortality. Rev Bras Cardiol Invasiva 2013; 21: 227-33. 
41. Yeh RW, Sidney S, Chandra M, et al. Population trends in the incidence and outcomes of acute myocardial infarction. N Engl J Med 2010; 362: 2155-65.

42. Antoni ML, Mollema SA, Delgado V, et al. Prognostic importance of strain and strain rate after acute myocardial infarction. Eur Heart J 2010; 31: 1640-7.

43. Eek C, Grenne B, Brunvand $\mathrm{H}$, et al. Strain echocardiography and wall motion score index predicts final infarct size in patients with non-ST-segment-elevation myocardial infarction. Circ Cardiovasc Imaging 2010; 3: 187-94. 